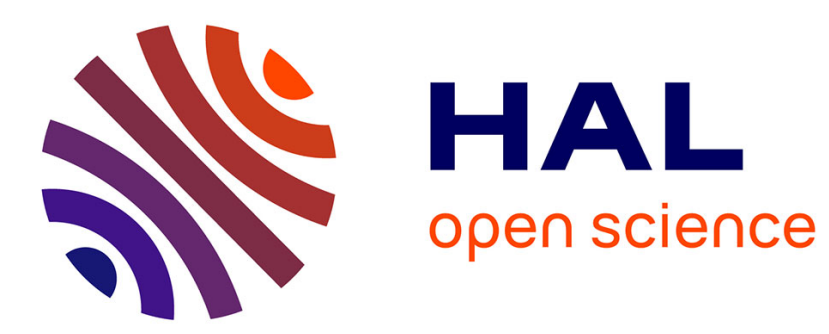

\title{
On the flexibility of an eco-industrial park (EIP) for managing industrial water
}

\author{
Ludovic Montastruc, Marianne Boix, Luc Pibouleau, Catherine \\ Azzaro-Pantel, Serge Domenech
}

\section{> To cite this version:}

Ludovic Montastruc, Marianne Boix, Luc Pibouleau, Catherine Azzaro-Pantel, Serge Domenech. On the flexibility of an eco-industrial park (EIP) for managing industrial water. Journal of Cleaner Production, 2013, vol. 43, pp. 1-11. 10.1016/j.jclepro.2012.12.039 . hal-00829374

\section{HAL Id: hal-00829374 \\ https://hal.science/hal-00829374}

Submitted on 3 Jun 2013

HAL is a multi-disciplinary open access archive for the deposit and dissemination of scientific research documents, whether they are published or not. The documents may come from teaching and research institutions in France or abroad, or from public or private research centers.
L'archive ouverte pluridisciplinaire HAL, est destinée au dépôt et à la diffusion de documents scientifiques de niveau recherche, publiés ou non, émanant des établissements d'enseignement et de recherche français ou étrangers, des laboratoires publics ou privés. 


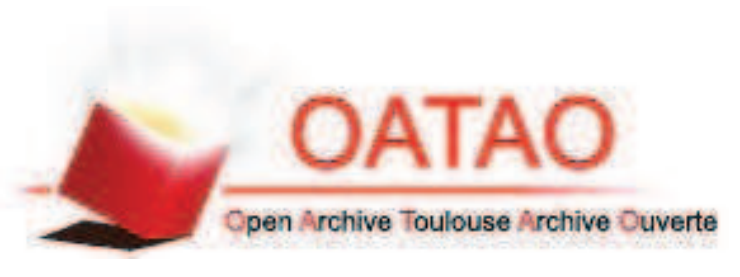

\section{Open Archive Toulouse Archive Ouverte (OATAO)}

OATAO is an open access repository that collects the work of Toulouse researchers and makes it freely available over the web where possible.

This is an author-deposited version published in: http://oatao.univ-toulouse.fr/ Eprints ID: 8524

To link to this article : DOI:10.1016/j.jclepro.2012.12.039

URL : http://dx.doi.org/10.1016/j.jclepro.2012.12.039

\section{To cite this version:}

Montastruc, Ludovic and Boix, Marianne and Pibouleau, Luc and AzzaroPantel, Catherine and Domenech, Serge On the flexibility of an eco-industrial park (EIP) for managing industrial water. (2013) Journal of Cleaner Production, vol. 43 . pp. 1-11. ISSN 0959-6526 


\title{
On the flexibility of an eco-industrial park (EIP) for managing industrial water
}

\author{
Ludovic Montastruc, Marianne Boix*, Luc Pibouleau, Catherine Azzaro-Pantel, Serge Domenech \\ Laboratoire de Génie Chimique (LGC), Centre National de la Recherche Scientifique (CNRS), Institut National Polytechnique de Toulouse (INPT), Université de Toulouse, \\ 4 Allée Emile Monso, BP 84234, 31432 Toulouse, France
}

\begin{abstract}
A B S T R A C T
In a recent paper, a generic model, based on a multiobjective optimization procedure, for water supply system for a single company and for an eco-industrial park was proposed and illustrated by a park involving three companies A, B and C. The best configuration was identified by simultaneously minimizing the fresh water flow rate, the regenerated water flow rate and the number of connections in the eco-industrial park. The question is now to know what the maximal increase/decrease in pollutant flow rates is, so that the eco-industrial park remains feasible, economically profitable and environmentally friendly. A preliminary study shows that the park can accept an increase of pollutant flow rates of $29 \%$ in company A, $12 \%$ in company B and only $1 \%$ in company C; beyond these limits the industrial symbiosis becomes not feasible. The proposed configuration is not flexible with a very limited number of connections. Indeed, the solution implemented for conferring some flexibility to this network is to increase the number of connections within the park. However, connections have a cost, so the increase of their number needs to remain moderate. The number of connections is augmented until the symbiosis becomes unfeasible, or until the gain for each company to participate to the park becomes lower than a given threshold. Several cases are studied by increasing the pollutant flow rates under two different scenarios: 1 ) in only one company, 2) in two or three companies simultaneously.
\end{abstract}

\section{Introduction}

Due to an increasing depletion of natural resources such as fresh water for instance, important environmental researches have been developed in the last decades. The environmental impact induced by the process industry is linked both to the high volumes involved and to the diversity of toxic products generated along the processing chain. Consequently, a real need to define optimized water networks so as to reduce the impact of contaminants on the environment, has recently emerged.

For a long time, studies dealing with the recycling of byproducts of an industry by another one appeared (Simmonds, 1862; Conover, 1918). These studies did not introduce any official term on what they dealt with. The concept of "Industrial Ecology" actually appeared in the 1970's (Hoffman, 1971) and Japanese and

Abbreviations: GAMS, General Algebraic Modeling System; MCDM, Multiple Choice Decision Making; MILP, Mixed Integer Linear Programming; MINLP, Mixed Integer Non Linear Programming.

* Corresponding author. Tel.: +335 343236 66; fax: +335 34323700 .

E-mail address: marianne.boix@ensiacet.fr (M. Boix).
Belgian studies went deeper in this topic (Watanabe, 1972). However, Frosh and Gallopoulos (1989) popularized this term twenty years ago from the idea that we should use the analogy of natural systems as an aid in understanding how to design sustainable industrial systems. As they indicate the ideal ecosystem, in which the use of energy and materials is optimized, wastes and pollution are minimized and there is an economically viable role for every product of a manufacturing process, will not be attained soon. It was true in 1989, and it is always true today, but to a lesser extent. Industrial Ecology has been defined by Allenby (2006) as "a systems-based, multidisciplinary discourse that seeks to understand emergent behavior of complex integrated human/natural systems". In most of the researches in Industrial Ecology the common guideline is that natural systems do not have waste in them, so our systems should be modeled from natural ones if we want them to be sustainable.

According to Chertow (2007), an industrial symbiosis engages "separate industries in a collective approach to competitive advantages involving physical exchange of materials, energy, water and by-products". This term is the subject of many debates due to its definition, difficult to formulate rigorously. However, a definition commonly adopted is "an industrial system of planned 


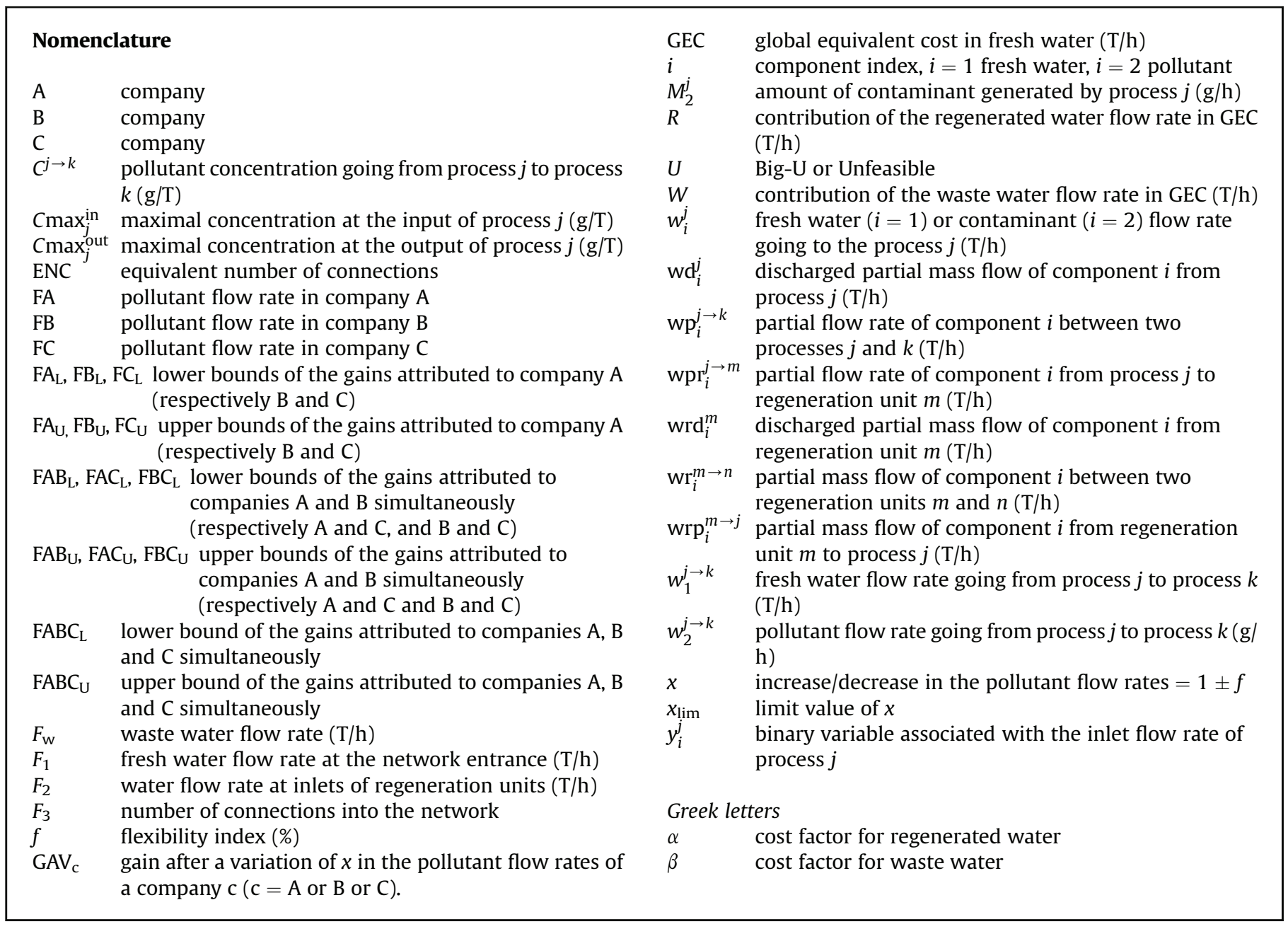

materials and energy exchanges that seeks to minimize energy and raw materials use, minimize waste, and build sustainable economic, ecological and social relationships" (PCSD, 1996; Alexander et al., 2000). Industrial symbiosis is a particular strategy for designing and implementing Eco-Industrial Parks (EIP).

Obviously, a basic condition so that an EIP is profitable, is to demonstrate that the sum of the gains (in terms of water consumptions) achieved by working as collective is higher than working as a stand-alone facility.

EIP problems for managing industrial water can be solved by mathematical programming procedures (Chew et al., 2008; Lovelady and El-Halwagi, 2009; Kim et al., 2010; Aviso et al., 2010a, b). Furthermore, a lot of research has been devoted to develop some indicators to evaluate the satisfaction of each participant of the EIP (Tiejun, 2010; Zhu et al., 2010). Other recent works implement the game theory for solving the problem (Chew et al., 2009, 2011). Several successful examples of industrial symbioses are located all around the world, particularly in North America (Côté and CohenRosenthal, 1998; Heeres et al., 2004; Gibbs and Deutz, 2005, 2007), Western Europe (Van Leeuwen et al., 2003; Baas and Boons, 2004; Heeres et al., 2004; Mirata, 2004), and Australia (Roberts, 2004; Van Beers et al., 2007; Van Berkel, 2007; Giurco et al., 2010). More recently, new eco-parks have been implanted in other emergent countries such as China (Geng and Hengxin, 2009; Liu et al., 2010; Shi et al., 2010), Brazil (Veiga et al., 2009) or Korea (Oh et al., 2005; Park et al., 2008). A good review of several successful EIPs had been presented by Tudor et al. (2007). Let us note that the great majority of the previous studies deal with some symbiotic relationship among industries which are only one particular strategy for implementing an EIP.

In a recent work, Boix et al. (2012) define a generic model for water supply system for a single company and for an EIP. The model is generic enough to be adapted to any problem of any size. An example involving three companies, containing each one five processes, first proposed by Olesen and Polley (1996), is used as illustration purpose. After studying several scenarios, the best configuration for the particular conditions studied was identified.

This present paper is dedicated to the study of the flexibility of the identified solution, that is to say its capacity to take sudden variations in pollutant flow rates. Indeed, a sensitivity analysis strategy of the proposed design for the EIP consisting of three companies is developed in this paper. It is assumed - apart from the number of connections - no change, like upgrading or adding regeneration units, changing processes, can occur in the EIP. In fact, the problem is to know what is the maximal increase/decrease in pollutant flow rates, so that the EIP remains feasible, environmentally friendly and profitable. Starting from the solution proposed by Boix et al. (2012), and increasing the number of connections, several cases are studied: increase/decrease of the pollutant flow rates in one company, in two and in the three ones. The problem is to identify connections between processes of the same company or linking two different companies, so as the EIP remains flexible in terms of variations in pollutant flow rates. It is assumed that the EIP involves only one key pollutant at different 
concentration levels; furthermore, companies can belong to different industrial sectors, and regeneration units of companies can treat their specific waste water and also streams from others.

For dealing with flexibility, two approaches are possible. The first one is to introduce directly flexibility constraints in the process design phase. In that case the optimization problem may become cumbersome in terms of size and CPU (Central Processing Unit) time (see Section 4.3.6), making very difficult the study of numerous scenarios (13 cases were analyzed in the previous paper of Boix et al., 2012). The second approach, implemented in this paper, consists in starting from a solution determined without any flexibility consideration, testing its flexibility, and if need be, making a revamping of this solution by considering only few scenarios.

Only a few publications deal with the flexibility of water networks and especially for EIP networks. The paper of Bansal et al. (2002) gives an interesting review of theoretical methods in this field. Concerning flexibility of water networks, one can cite the work of Ramirez (2002) related to capital budgeting techniques for expansion of a water supply system; the report USC (2002) where it is mentioned that flexibility is the ability to create effluents of various qualities and quantities for tenant firms; the report ACE 12/ 2005; the conference paper of Zhang and Babovic (2009), and finally the paper of Chang and Riyanto (2010), where the revamping of water networks includes inserting/deleting pipeline connections. This last approach is adopted in this study.

The aim of this paper, based on a particular example, is to give some guidelines for performing a flexibility analysis of an existing EIP. The main academic contributions are the implementation of linear multiobjective optimization for identifying the best solutions corresponding to different scenarios and the use of two indicators for performing the choice of some particular solutions. Furthermore in practice, it often happens that some input parameters are subject to a lot of variations, the goal is then to analyze the consequences of these variations and uncertainties.

Finally, another academic aim is the development of a generic approach that can be adapted for studying the flexibility analysis in terms of water supply system for any EIP. On a practical point of view, the approach can be implemented in an EIP of any size.

\section{Numerical procedure}

\subsection{MILP problem statement}

Given a set of regeneration units and processes, the objective is to determine a network of connections of water streams among them so that both the overall fresh water consumption $\left(F_{1}\right)$, the regenerated water flow rate $\left(F_{2}\right)$ and the number of connections $\left(F_{3}\right)$ are simultaneously minimized. Each process has limited inlet and outlet concentrations, and regeneration units are defined by their outlet concentration. The particular case of an EIP can be viewed to a bigger company divided into blocks (each block being in fact a company). The purpose is to design an optimal network for an EIP where all the requirements in terms of contaminant concentrations for each process are respected.

\subsection{Superstructures definition}

In a company superstructure, all the possible connections between processes and/or regeneration units may exist, except recycling to the same regeneration unit or process. For each waterusing process, input water may be fresh water, used water coming from other processes and/or recycled water; the output water for such a process may be sent toward the discharge, or to other processes and/or to regeneration units. Similarly, for a regeneration unit, input water may come from processes or from other regeneration units. Regenerated water may be reused in the processes or sent toward other regeneration units (Fig. 1a).

A process $j$ generates a mass of contaminant due to its own working. This contamination is expressed in $\mathrm{g} / \mathrm{h}$ and its value is fixed by the user. By concern of generalization, the problem is built as a set of black boxes, in order to adapt the formulation to a great variety of practical cases. In this black box approach, the role (physical or chemical transformation) of each process within the network is not taken into account. For each process input or output contaminant mass fractions ( $\mathrm{ppm}$ ) are imposed by the user, and constitute bounds for the optimization problem. To sum up, a process unit is only characterized by maximal inlet and outlet concentrations in ppm and a contaminant flow rate in $\mathrm{kg}$ per hour. It is typically a problem that deals with fixed load processes that can be described as mass transfer processes, e.g. washing, extraction or scrubbing.

The same superstructure is also adopted for an EIP (Fig. 1b) and the connections between the different companies will be defined in the following sections.

\subsection{Process modeling}

In most of previous works, the water allocation problem is generally solved with a Mixed Integer Non Linear Programming (MINLP) optimization procedure (Feng et al., 2008). Indeed, the problem formulation contains bilinear terms due to products in mass balances for contaminants. These bilinearities are caused by products of concentrations and flow rates (Sienutycz and Jezowski, 2009).

In this study, the formulation is based upon the necessary conditions of optimality developed by Savelski and Bagajewicz (2000) which relies on the elimination of these bilinearities for a single contaminant water network. The modeling equations, involving partial mass flows, that is to say that contaminants are represented by flow rates (in $\mathrm{g} / \mathrm{h}$ ) instead of concentrations (in $\mathrm{ppm}$ ), and are given in Appendix. The model formulation is the same as in the previous study of Boix et al. (2011b).

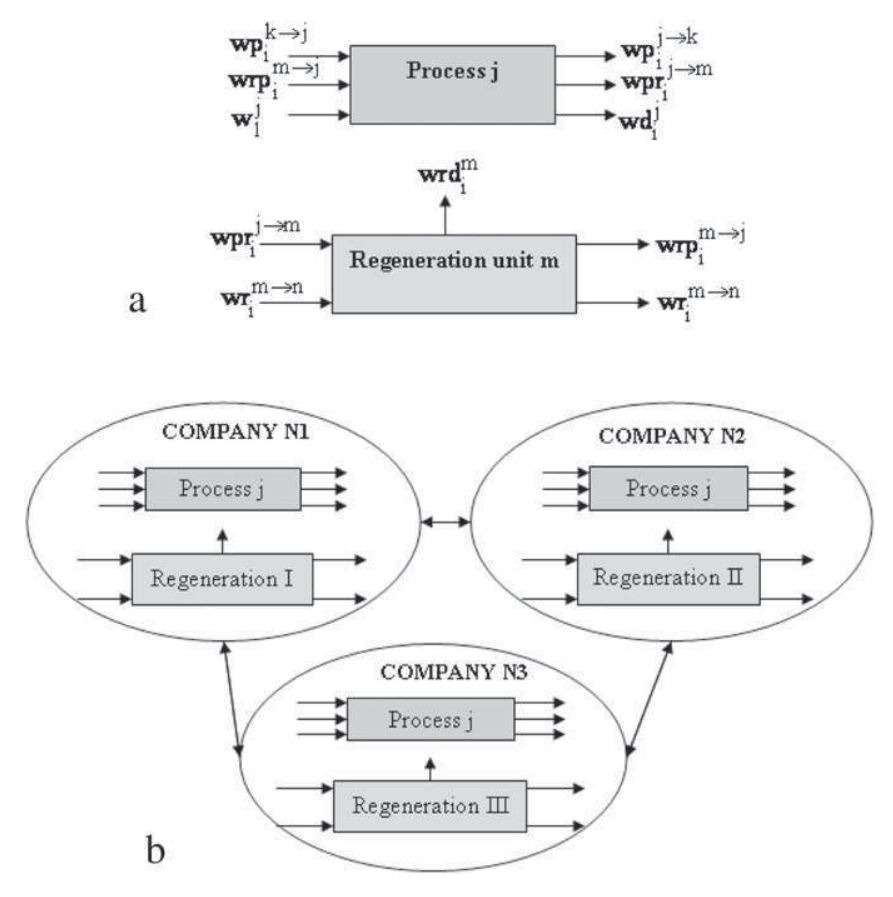

Fig. 1. Superstructures for a company (a), and an EIP involving three companies (b). 


\subsection{Multiobjective optimization}

The main goal of multiobjective optimization is to provide good trade-offs between conflicting objectives by using for instance the notion of non domination (see equation (4)). Multiobjective optimization makes part of our current life; for example when a customer buys a car, he tries to reach a satisfactory compromise between the investment cost and the operating cost.

As it involves real variables (flow rates) and binary ones (existence of connections), the problem is a mixed-integer one. By using partial flow rates instead of concentrations and the necessary conditions of Savelski and Bagajewicz (2000), the set of constraints defined in Appendix is linear. The considered objectives to be simultaneously minimized are the fresh water flow rates at the network entrances $F_{1}$, the water flow rates at inlets of regeneration units $F_{2}$. They are conflicting ones, because if the fresh water flow rate is decreased, the regenerated water flow has to be increased. Let us note that $F_{1}$ and $F_{2}$ are expressed linearly in terms of flow rates. Insofar as it involves linear objectives submitted to a linear set of constraints, the problem is a biobjective MILP (Mixed Integer Linear Programming) one. Another objective is the number of connections into the network, $F_{3}$, expressed as a sum of binary variables. $F_{3}$ is deliberately formulated in terms of connections number, because if a cost is attributed, the objective function linked to connections does not follow a linear formulation (see Sienutycz and Jezowski, 2009). As in practice, $F_{3}$ covers a restricted range of integer values, the biobjective problem $\operatorname{Min}\left(F_{1}, F_{2}\right)$ was solved by considering several values of $F_{3}$ as additional linear equality constraints.

When dealing with multiobjective optimization, the classical optimality conditions of Kuhn-Tucker developed in the monobjective case do not hold, because $R^{n}$ is not provided with a total relation order, for $n \geq 2$. The solution, generally adopted consists in defining a set of non dominated solutions, also called a Pareto front. A general multiobjective optimization problem is formulated as:

$\operatorname{Min} F(x)=\left[f_{1}(x), f_{2}(x), \ldots, f_{p}(x)\right]^{T}$

where $x \in X \subset R^{n} \times N^{m}$

The subspace $X$ is defined by a set of equality-inequality constraints:

$$
\begin{aligned}
& X=\left\{x \in R^{n} \times N^{m} / g_{i}(x) \leq 0, i=1 \text { to } r ; h_{j}(x)=0,\right. \\
& j=1 \text { to } s ; l(i) \leq x(i) \leq u(i)\}
\end{aligned}
$$

The Pareto optimal or non dominated solutions are the solutions that cannot be improved in one objective function without deteriorating the performance in at least one of the other objectives. The mathematical definition of a Pareto solution is the following: a feasible solution $x^{*}$ of the multiobjective optimization problem is non-dominated if there is no other feasible solution $x$ such as:

$f_{i}(x) \leq f_{i}\left(x^{*}\right) \forall i \in\{1, \ldots, p\}$

with at least one strict inequality. The set of non dominated solutions constitute the Pareto front, i.e. the set of problem solutions amongst which the decision maker has to perform his choice. Several Multiple Criteria Decision Methods are available in the literature, one of the most popular one being TOPSIS (Chen et al., 2009). TOPSIS is an evaluation method where the distance between available solutions and the 'optimized ideal reference point' is calculated. The optimized ideal reference point is a theoretical point where both objectives are at their minimal values. This program calculates this distance and ranks them by increasing order of distance.

\subsection{Comparison strategy}

In what follows, internal connections refer to connections between processes of the same company and external connections (between two companies) are related to connections coming from or going toward other companies. The industrial symbiosis in the park comes into play through these external connections. By supposing constant distances between companies, it is assumed that for each external connection, the cost for each company is divided by two. If distances are different a convex weighted sum of the number of external connections can be used in relation (5). For EIPs involving an interceptor for sharing regeneration units, the connections between a given company and the interceptor are considered as external connections. Thus, the Equivalent Number of Connections (ENC) for a given company, which reflects the complexity of the associated infrastructure, is given by:

$$
\begin{aligned}
\mathrm{ENC}= & \text { number or internal connections }+0.5 \\
& \times \text { number of external connections }
\end{aligned}
$$

The number of connections has a significant economic impact, as it is shown in Chew et al. (2008) and Boix et al. (2012) (see Section 4.3.2).

Another economic indicator, the Global Equivalent Cost (GEC) in fresh water flow rate, was defined (Boix et al., 2011a). This cost is expressed as an equivalent of fresh water flow rate in $T / h$. For comparison purposes, we could use the prices of fresh water, of regenerated water and of post-treatment in the waste, which represents the cost for treating polluted water (costs of plants, of chemicals, manpower) before recycling it. However, these prices are strongly linked to the country and even to regions of a given state.

$\mathrm{GEC}=F_{1}+R+W$

where $F_{1}$ is defined above, $R$ and $W$ are the contributions of regenerated and waste waters, with:

$R=\alpha \times F_{2}$ and $W=\beta \times F_{\mathrm{W}}$

where $F_{\mathrm{w}}$ is the waste water flow rate.

Combining relations (6) and (7) leads to the following relation:

$\mathrm{GEC}=F_{1}+\alpha \times F_{2}+\beta \times F_{w}$

In the previous relations, $\alpha$ depends on the type of regeneration unit (see Table 1 ) and $\beta=5.625$ according to Bagajewicz and Faria (2009).

After the multiobjective optimization step, the different solutions are discriminated by performing a Pareto front sorting on couples (GEC, ENC) for each company, which are related to the economic dimension of the EIP. In fact, by implementing a biobjective optimization a Pareto front is obtained instead of a single solution as in the monobjective case (with the total cost to be

Table 1

Values of $\alpha$ according to types of regeneration units.

\begin{tabular}{lll}
\hline Regeneration type & Outlet concentration $(\mathrm{ppm})$ & $\alpha$ value \\
\hline I & 50 & 0.375 \\
II & 20 & 1.75 \\
III & 5 & 3.125 \\
\hline
\end{tabular}


minimized for instance). Here all the results provided by the biobjective optimization are presented first and a tool for decision aid is then used for determining the set of "best" solutions. The advantage of this method is to provide results, without any preference a priori on objectives and that can be treated with several Multiple Choice Decision Making (MCDM) tools. Furthermore, if a cost is considered as an objective function, the multiobjective optimization problem cannot remain linear. It is worth noting that the results provided by the Pareto front can be evaluated in terms of cost in the post-optimization stage, by introducing the cost as a supplementary item in the MCDM procedure.

\section{Best EIP}

\subsection{Problem formulation}

The example proposed by Olesen and Polley (1996), is used as illustration purpose. The industrial pool involves three companies, each one including five processes; the data are displayed in Table 2 .

In a preliminary study (Boix et al., 2012), the water network was designed for each company without considering the EIP in order to determine the best regeneration unit chosen by each company among the three types listed in Table 3. From this multiobjective optimization study (objectives $F_{1}, F_{2}$ and with constraint $F_{3}$ ), the best solution is obtained when companies $A$ and $B$ choose regeneration unit $\mathrm{I}$, and company $\mathrm{C}$, regeneration unit II. This solution is given by the median point of the Pareto front $\left(F_{1}, F_{2}\right)$ for the minimal value of $F_{3}$ (reference case 0 of Table 4).

The three companies decide to pursuit an industrial symbiosis for managing their used waters inside an EIP. The superstructure of the EIP is shown in Fig. 2. The objective is to identify the best strategy for each company so as to minimize the global equivalent cost (GEC) and the number of connections in the network (ENC). For each scenario, several situations were analyzed: different gains for companies, restricted number of connections, and same gain for all the companies. The major constraint is that the EIP has to be economically profitable, that is to say, the gains for each company must be positive.

\subsection{Problem solution}

In a first step, the range of possible values for the number of connections $F_{3}$ in the EIP is defined. Then the water allocation problem consists in solving the biobjective problem Min $\left(F_{1}, F_{2}\right)$

Table 2

Process characteristics for the EIP.

\begin{tabular}{llccc}
\hline Process & Company & $\begin{array}{l}\text { Pollutant flow } \\
\text { rate }(\mathrm{kg} / \mathrm{h})\end{array}$ & $\begin{array}{l}\text { Maximal inlet } \\
\text { concentration } \\
(\mathrm{ppm})\end{array}$ & $\begin{array}{l}\text { Maximal outlet } \\
\text { concentration } \\
(\mathrm{ppm})\end{array}$ \\
\hline 1 & A & 2 & 0 & 100 \\
2 & 2 & 50 & 80 \\
3 & & 50 & 100 \\
4 & 5 & 80 & 800 \\
5 & & 400 & 800 \\
6 & $\mathrm{~B}$ & 2 & 0 & 100 \\
7 & & 2 & 50 & 80 \\
8 & 5 & 80 & 400 \\
9 & & 30 & 100 & 800 \\
10 & & 400 & 1000 \\
11 & $\mathrm{C}$ & 2 & 0 & 100 \\
12 & & 2 & 25 & 50 \\
13 & 5 & 25 & 125 \\
14 & & 50 & 150 \\
15 & 30 & 100 & \\
\hline
\end{tabular}

Table 3

Different types of regeneration units.

\begin{tabular}{ll}
\hline Regeneration type & Outlet concentration $(\mathrm{ppm})$ \\
\hline I & 50 \\
II & 20 \\
III & 5 \\
\hline
\end{tabular}

under the constraint $F_{3}$ fixed at a given value in the previous range. The multiobjective method based on the $\varepsilon$-constraint two-phase strategy (Mavrotas, 2009), was implemented (details are given in Boix et al., 2012). For each biobjective solution, the median point of the Pareto front is retained if it does not involve connections with flows lower than $2 \mathrm{~T} / \mathrm{h}$ (for avoiding using very small pipes, with diameter less than one inch). If this constraint does not hold for the median solution, a neighboring solution is chosen on the Pareto front.

Using this optimization strategy, the best solution among the several scenarios was identified for the EIP. Two main scenarios were studied: EIP with one regeneration unit per company (direct integration) and EIP with a common regeneration unit (indirect integration), and for each scenario several cases (restricted number of connections, same or different gains for companies). This best solution (case 1) corresponds to a direct integration strategy (private regeneration units) for this particular network.

The results are displayed in Table 4, where the gains are computed vs. the reference case, case 0 . This case corresponds to standalone companies (not included in the EIP), with private regeneration units (Type I for A and B, type II for C, Boix et al., 2012). In the proposed solution, it was imposed that the three companies have the same gain vs. case 0 . The flowsheet of the EIP for the best solution is shown in Fig. 3 (internal flow rates and connections to the waste are not reported).

\subsection{Computational aspects}

The computations were carried out on an Intel Duo Core $2.53 \mathrm{GHz}$, RAM $3.45 \mathrm{Go}$. The MILP problem was solved with the solver CPLEX 11.2.1 of GAMS (General Algebraic Modeling System) package. GAMS is a high-level modeling system for mathematical programming and optimization and it consists in a language compiler and in a library involving various solvers. The problem related to case 1 involves 1164 continuous variables, 357 integer ones, 1312 constraints and requires $0.14 \mathrm{~s}$ of CPU time.

\section{Flexibility study}

\subsection{Preliminary study}

This flexibility study consists in exploring the different decisions that the user can make under uncertainties. The question can be

Table 4

Results for the EIP solution.

\begin{tabular}{lllrlll}
\hline Case & $F_{1} \mathrm{~T} / \mathrm{h}$ & $F_{\mathrm{w}} \mathrm{T} / \mathrm{h}$ & $F_{2} \mathrm{~T} / \mathrm{h}$ & GEC T/h & $\begin{array}{l}\text { Gain } \% \\
\text { vs. Case 0 }\end{array}$ & $\begin{array}{l}\text { Int. + Ext. } \\
\text { conn }\end{array}$ \\
\hline A case 0 & 20 & 20 & 166 & 195 & XXXX & 8 \\
A case 1 & 20 & 15 & 167 & 168 & 13.8 & 7 \\
B case 0 & 20 & 20 & 67 & 157 & XXXX & 8 \\
B case 1 & 20 & 12 & 128 & 135 & 13.8 & 9 \\
C case 0 & 20 & 20 & 192 & 469 & XXXX & 10 \\
C case 1 & 20 & 33 & 114 & 404 & 13.8 & 10 \\
Total case 0 & 60 & 60 & 425 & 821 & XXXX & 26 \\
Total case 1 & 60 & 60 & 409 & 708 & 13.8 & 26 \\
\hline
\end{tabular}




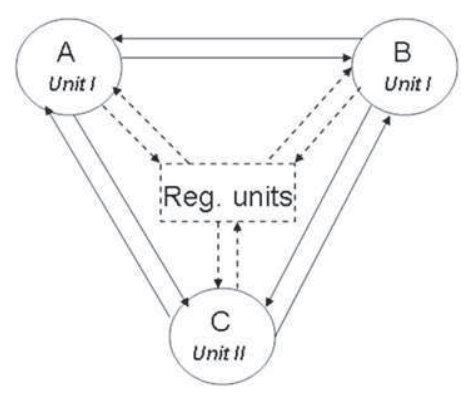

Fig. 2. Representation of the EIP for the three companies (straight lines: direct integration, dash lines: indirect integration).

formulated as follows: "What are the consequences of some changes in the pollutant flow rates in terms of decision making?" According to Swaney and Grossmann (1985), one can define a flexibility index as a measure of the maximum tolerable range of variation in every uncertain parameter (here, the contaminant flow rates for every process unit in the network). In the previous section, the problem was solved for fixed values of the pollutant flow rate for each process of each company (see Table 2). The question which arises now is to know what is the maximal increase/decrease of pollutant flow rates, so that the existing EIP remains feasible and profitable.

Several cases have to be studied: flow rate variations in one, two or three companies. In the EIP, it is important to constrain each company to have the same gain. In the following tables, notation $\mathrm{FA}^{*} x$ means that the pollutant flow rates FA of company A (third column of Table 2 ) are multiplied by $x$, and $(\mathrm{FA}+\mathrm{FB})^{*} x$ means that the pollutant flow rates FA of company A and FB of company $B$ are multiplied by $x$.

The value of $x$ is determined by a simple dichotomy procedure. For example, considering an increase of the flow rates in company A, and assuming $x \in[1,2]$, if for $x=2$, the EIP is unfeasible or has a gain less or equal a given threshold, $x$ is replaced by 1.5 , and so on.

The Gain After a Variation of $x\left(\mathrm{GAV}_{\mathrm{c}}\right)$ for a company $\mathrm{c}(\mathrm{c}=\mathrm{A}, \mathrm{B}$ or $\mathrm{C})$ is computed according to the following expression:

$\mathrm{GAV}_{\mathrm{c}}=\left(x^{*} \mathrm{GEC}_{\mathrm{c}}\right.$ in case $\left.0-\mathrm{New} \mathrm{GEC}_{\mathrm{c}}\right) /\left(x^{*} \mathrm{GEC}_{\mathrm{c}}\right.$ in case 0$)$
Table 5

Limits for the increase $x$ and gains after increase.

\begin{tabular}{lll}
\hline & $x_{\lim }$ & GAV \\
\hline $\mathrm{FA}^{*} x$ & 1.29 & 13.7 \\
$\mathrm{FB}^{*} x$ & 1.12 & 13.5 \\
$\mathrm{FC}^{*} x$ & 1.01 & 13.8 \\
\hline
\end{tabular}

where New $\mathrm{GEC}_{\mathrm{c}}$ is the GEC for a company $c$, computed by optimizing the flow rates in the EIP (with fixed number of connections, for example, for case 1, the value is set at 26).

Let us note that if the pollutant flow rates in a company are multiplied by $x$, insofar as the outlet concentrations are fixed at their maximal values (theorems of Savelski and Bagajewicz, 2000), all the flows are multiplied by $x$. So, after an increase of $x$, the GEC is also multiplied by $x$. It is the same case for a decrease.

For case 1, the gains of the three companies vs. the reference case 0 (GEC in case 0 ) is $13.8 \%$ for $x=1$ (see Table 4 ). The values of GAV related to case 1 (best solution, one regeneration unit per company, 26 connections) are displayed in Table 5. The limit value of $x, x_{\text {lim }}$, reported in this Table, corresponds to the limit beyond which the network becomes unfeasible for performing the polluted water treatment.

The flexibility of company $C$ is near zero. For an increase $x$ greater than 1.01, the EIP of case 1 becomes unfeasible. The EIP network being flexible in no way, we did not pursue further this study with an increase of the pollutant flow rates for companies $A \& B, A \& C, B \& C, A \& B \& C$. Indeed, the lack of flexibility comes from the fact that company $C$ is more demanding than the two other ones in terms of pollutant loads to be treated.

\subsection{Discussion}

In fact, we find again a classical situation, when process design is carried out by means of sophisticated numerical optimization procedures. In this particular case, the problem is very constrained (the number of connections is very low) and this is the reason why we obtain one solution that cannot be changed. The solution is located in a very narrow valley, where a slight movement leads on the wall of the mountain (see Fig. 4) and at this moment, the

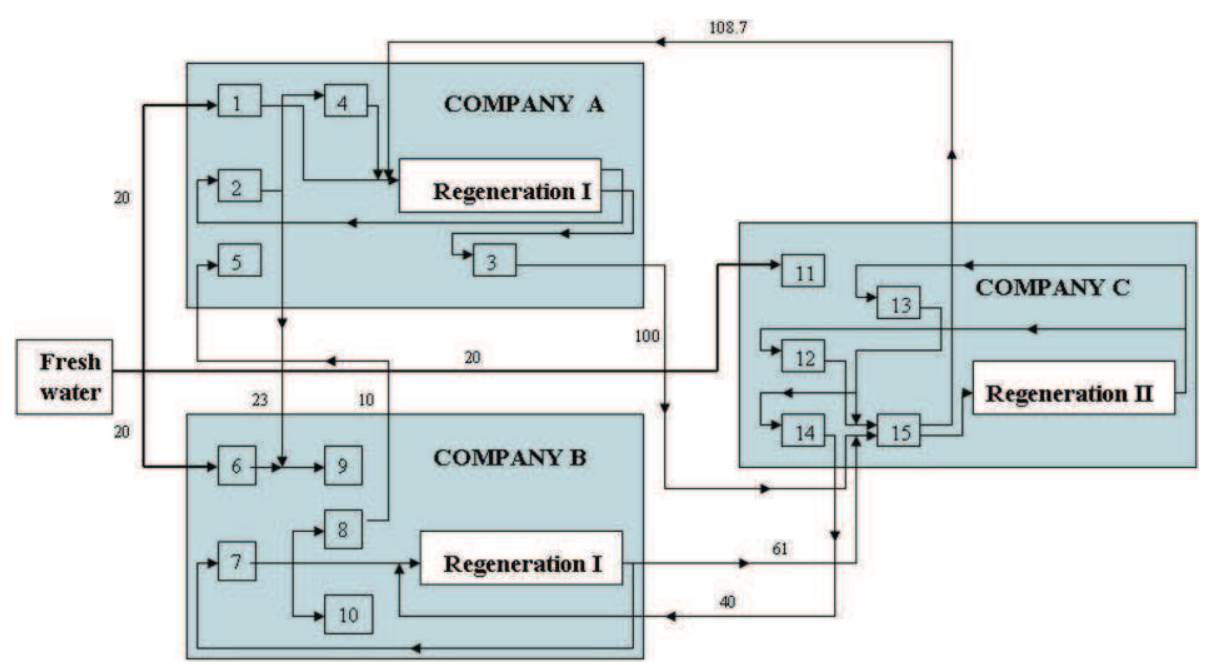

Fig. 3. EIP solution (case 1, flows are in $\mathrm{T} / \mathrm{h}$ ). The outputs of units 5, 9, 10 and 11 going to the waste are not represented. 
Table 6

EIP for different values of the flexibility index $f$ (U: unfeasible for at least one company). Gains are expressed in \%.

\begin{tabular}{llll}
\hline $\begin{array}{l}\text { Nb internal } \\
\text { connections }\end{array}$ & $\begin{array}{l}\text { Gain vs. } \\
\text { Case } 0 f=0.1\end{array}$ & $\begin{array}{l}\text { Gain vs. } \\
\text { Case } 0 f=0.25\end{array}$ & $\begin{array}{l}\text { Gain vs. } \\
\text { Case } 0 f=0.5\end{array}$ \\
\hline 21 & 13.7 & 12.1 & $\mathrm{U}$ \\
22 & 15.3 & 13.8 & $\mathrm{U}$ \\
23 & 15.3 & 15.2 & $\mathrm{U}$ \\
24 & 15.4 & 15.4 & 15.2 \\
\hline
\end{tabular}

problem becomes unfeasible. The best EIP identified by the biobjective optimization $\operatorname{Min}\left(F_{1}, F_{2}\right)$ corresponds to the minimal value of GEC, for the minimal value of internal and external connections (26).

The only solution to return the proposed network flexible is to increase the number of connections. Let us note that only internal connections are concerned, insofar as it is assumed that each company has always two external input and two external output connections (see Fig. 2). However, it must be kept in mind that connections have a cost, so the increase of the number of connections needs to remain moderate. We have limited it at 30 connections (24 internal ones) for all the EIP. As it can be observed in Table 7, the connection costs represent a significant part of the fresh water cost: $35 \%$ for 20 internal connections, $42 \%$ for 24 internal connections; that is the reason why the internal connections were restricted to 24 .

\subsection{Increasing the number of connections}

\subsubsection{Network definition}

Starting from the solution of case 1 involving 26 connections (20 internal connections), the number of internal connections is now progressively increased for different values of the factor $x$. This increase is pursued, either until the gains vs. case 0 reach thresholds, fixed for example at about $10 \%$ for an increase in the pollutant flow rates and about $5 \%$ in the case of a decrease, or when the network becomes unfeasible. We admit that beyond these thresholds, companies do not have any economic interest to be involved into this industrial symbiosis. The flexibility index $f(\%)$ is used for expressing the variation of the pollutants flow rates under the form:

$x=1 \pm f$

For a given number of internal connections greater than 20 and a fixed value of the flexibility index $f$, the EIP network is designed

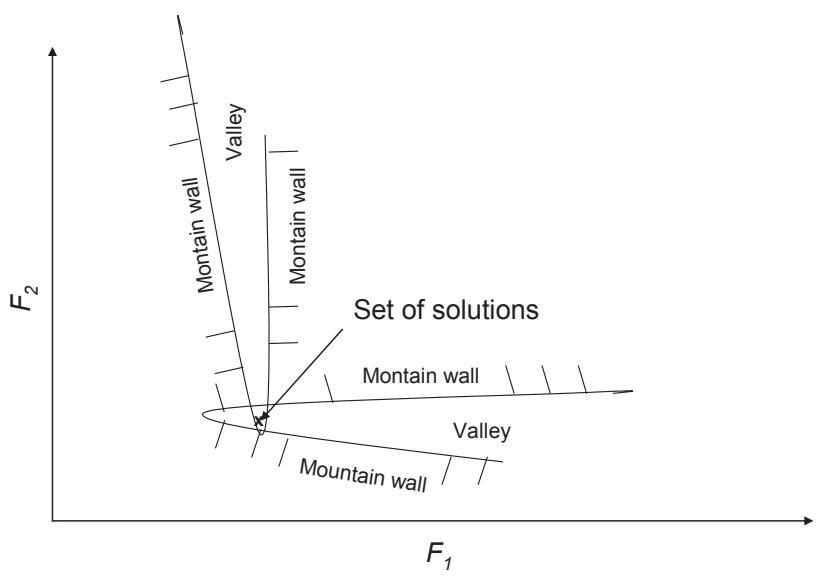

Fig. 4. Biobjective solutions for the EIP (for fixed $F_{3}$ ).
Table 7

Estimation of the internal piping cost (\% vs. fresh water cost).

\begin{tabular}{llllll}
\hline Nb internal connections & 20 & 21 & 22 & 23 & 24 \\
\hline Piping cost vs. fresh water cost (\%) & 35.0 & 36.75 & 38.5 & 40.25 & 42.0 \\
\hline
\end{tabular}

again by optimizing the pair $\left(F_{1}, F_{2}\right)$, without considering a variation of the pollutant flow rates, but by taking into account 14 flexibility constraints stating that the EIP network has to be feasible for pollutant flow rates $\mathrm{FA}^{*} x, \mathrm{FB}^{*} x, \mathrm{FC}^{*} x,(\mathrm{FA}+\mathrm{FB})^{*} x,(\mathrm{FA}+\mathrm{FC})^{*} x,(\mathrm{FB}+\mathrm{FC})^{*} x$ and $(\mathrm{FA}+\mathrm{FB}+\mathrm{FC})^{*} x$, where $x=1 \pm f$. The results are displayed in Table 6, where symbol $U$ means that the network is unfeasible with respect to at least one flexibility constraint. The study is carried out for three values of $f$, low value (0.1), mean value (0.25) and high value (0.5).

For the same number of internal connections, the gains depend on the flexibility index $f$. For instance, when $f$ passes from 0.1 to 0.25 , the feasibility constraints become more stringent, the search space is reduced and the optimal values of GEC increase what causes a decrease of the gain. Let us recall that the aim being to minimize the GEC, when it increases, the gain vs. Case 0 decreases. Furthermore, the gains increase with the number of connections; it results from the fact that we did not take into account the extra cost related to added connections, for computing the gains only the GEC was considered.

\subsubsection{Economic impact of the number of internal connections}

An indicative study coming from Chew et al. (2008) and Boix et al. (2012), was carried out for a company involving one regeneration unit, five processes, and eight connections. It was assumed a mean length of internal pipes of $50 \mathrm{~m}$, a fractional interest rate of $5 \%$, a period of 5 years and a fresh water cost of $0.1 € / T$ (cost of river water). The ratio (piping cost/fresh water cost) is $14 \%$, that is to say $1.75 \%$ per connection.

Note that when EIPs are considered, the part due to external connections which are much longer (there is at least a factor 10) than the internal ones, significantly increases the ratio (piping cost/ fresh water cost). However, in this study, only internal connections are added in the EIP network.

Starting from the EIP involving 20 internal connections and six external ones (case 1), the extra cost due to supplementary internal connections are reported in Table 7.

\subsubsection{Variations of the pollutant flow rates in one company}

The goal is now to provide some guidelines for choosing a satisfactory balance between flexibility and the number of connections. A study of gains for each company is presented in Table 8, where $\mathrm{FA}_{\mathrm{L}}$ (respectively $\mathrm{FA}_{\mathrm{U}}$ ) represents $\mathrm{FA}^{*}(1-f)$ (respectively $\left.\mathrm{FA}^{*}(1+f)\right)$. As in Table 6 , the gains for a given company increase with the number of internal connections, and for each company, the gains $L$ are lesser than the gains $U$, because the flow rates are lesser, as well as the gains. The gains of each company are calculated with the help of equations (11)-(24):

$$
\begin{aligned}
& \mathrm{FA}_{\mathrm{L}}=\mathrm{FA}^{*}(1-f) \\
& \mathrm{FA}_{\mathrm{U}}=\mathrm{FA}^{*}(1+f) \\
& \mathrm{FB}_{\mathrm{L}}=\mathrm{FB}^{*}(1-f) \\
& \mathrm{FB}_{\mathrm{U}}=\mathrm{FB}^{*}(1+f)
\end{aligned}
$$


Table 8

a. Gains after variation for $f=0.10$. b. Gains after variation for $f=0.25$. c. Gains after variation for $f=0.50$ (U: unfeasible).

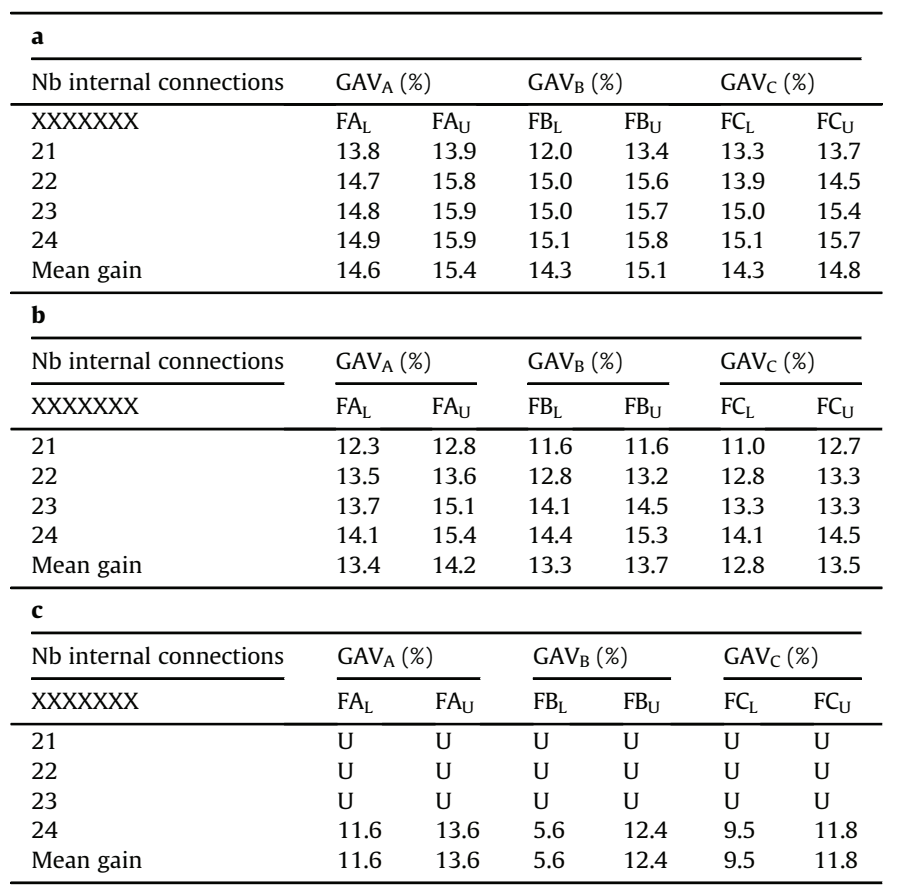

$\mathrm{FC}_{\mathrm{L}}=\mathrm{FC}^{*}(1-f)$

$\mathrm{FC}_{\mathrm{U}}=\mathrm{FC}^{*}(1+f)$

$\mathrm{FAB}_{\mathrm{L}}=(\mathrm{FA}+\mathrm{FB}) *(1-f)$

$\mathrm{FAB}_{\mathrm{U}}=(\mathrm{FA}+\mathrm{FB})^{*}(1+f)$

$\mathrm{FAC}_{\mathrm{L}}=(\mathrm{FA}+\mathrm{FC})^{*}(1-f)$

$\mathrm{FAC}_{\mathrm{U}}=(\mathrm{FA}+\mathrm{FC}) *(1+f)$

$\mathrm{FBC}_{\mathrm{L}}=(\mathrm{FB}+\mathrm{FC}) *(1-f)$

$\mathrm{FBC}_{\mathrm{U}}=(\mathrm{FB}+\mathrm{FC}) *(1+f)$

$\mathrm{FABC}_{\mathrm{L}}=(\mathrm{FA}+\mathrm{FB}+\mathrm{FC}) *(1-f)$

$\mathrm{FABC}_{\mathrm{U}}=(\mathrm{FA}+\mathrm{FB}+\mathrm{FC})^{*}(1+f)$

Obviously, the mean gains decrease when the flexibility index $f$ increases. When passing from a low flexibility level $(f=0.1)$ to

Table 9

Lower and upper values for the GEC.

\begin{tabular}{llc}
\hline GEC for: & Scenario $1(\mathrm{~T} / \mathrm{h})$ & Scenario $2(\mathrm{~T} / \mathrm{h})$ \\
\hline $\mathrm{FA}_{\mathrm{L}}$ & 126.1 & 86.2 \\
$\mathrm{FA}_{\mathrm{U}}$ & 206.9 & 272.7 \\
$\mathrm{FB}_{\mathrm{L}}$ & 101.1 & 74.1 \\
$\mathrm{FB}_{\mathrm{U}}$ & 167.8 & 206.3 \\
$\mathrm{FC}_{\mathrm{L}}$ & 304.9 & 212.2 \\
$\mathrm{FC}_{\mathrm{U}}$ & 508.3 & 620.5 \\
\hline
\end{tabular}

Table 10

Gains for two companies in scenarios 1 and 2 .

\begin{tabular}{|c|c|c|c|c|c|c|}
\hline \multirow[t]{2}{*}{ Scenario } & \multicolumn{2}{|c|}{$\mathrm{GAV}_{\mathrm{AB}}(\%)$} & \multicolumn{2}{|c|}{$\mathrm{GAV}_{\mathrm{AC}}(\%)$} & \multicolumn{2}{|c|}{$\mathrm{GAV}_{\mathrm{BC}}(\%)$} \\
\hline & $\mathrm{FAB}_{\mathrm{L}}$ & $\mathrm{FAB}_{U}$ & $\mathrm{FAC}_{\mathrm{L}}$ & $\mathrm{FAC}_{U}$ & $\mathrm{FBC}_{\mathrm{L}}$ & $\mathrm{FBC}_{\mathrm{U}}$ \\
\hline 1 & 13.9 & 14.8 & 13.4 & 13.8 & 13.5 & 13.6 \\
\hline 2 & 8.9 & 13.1 & 10.1 & 12.3 & 8.5 & 12.0 \\
\hline
\end{tabular}

a mean flexibility level $(f=0.25)$, this decrease being small, the lower level of flexibility is not any more considered. To pursue the flexibility study, the cases $(f=0.25$, number of internal connections $=23-$ scenario 1$)$ and $(f=0.5$, number of internal connections $=24-$ scenario 2 ) have been retained. Let us note that when passing to 20 internal connections as in the case 1, to 23 in scenario 1 (respectively to 24 in scenario 2 ), the extra cost due to the increase of the number of connections is estimated at $5.25 \%$ (respectively 7\%) in terms of fresh water cost (see Table 7).

\subsubsection{Variations of the pollutant flow rates in two companies}

If the pollutant flow rate variations are planned to occur into two companies $(A B)$, or $(A C)$, or $(B C)$, the problem is now to know if the EIP structure identified in scenario 1 (respectively scenario 2 ) remains economically profitable.

The lower and upper values for the GEC are displayed in Table 9; they are computed according to relation (9), where the GAV is known from Table 8. For example, New $\mathrm{GEC}_{\mathrm{AL}}$ is given by $\left(\left(0.75^{*} 195\right)-\right.$ New $\left.\mathrm{GEC}_{\mathrm{AL}}\right) /\left(0.75^{*} 195\right)=0.137$, that is to say, New $\mathrm{GEC}_{\mathrm{AL}}=126.1$

The results for the GAV are reported in Table 10. For example in scenario 1 , from Tables 4 and 9 , the GAV for $A B_{L}$ is computed as follows: $\mathrm{GAV}_{\mathrm{ABL}}=\left(0.75^{*}(195+157)-(126.1+101.1)\right) /$ $\left(0.75^{*}(195+157)\right)=13.9$. From Table 10 , the two scenarios are economically viable. The gains in GAV and the extra cost due to the number of connections are better for scenario 1 than for scenario 2 , but scenario 2 offers more flexibility.

\subsubsection{Variations in the three companies}

This is the more general case, where the economic analysis does not allow targeting one or two particular companies. The pollutant flow rate variations can occur in the three companies; the results are reported in Table 11. Concerning the comparison of the two scenarios, the conclusion is the same as in the previous case. The EIP flowsheet corresponding to scenario 1 is presented in Fig. 5, where the connections to the waste are not reported, as well the flow rates which are dependant from the studied case (a single company, two companies and the three ones).

\subsubsection{Computational aspects}

The problem dimension explodes as well as the CPU time; this is mainly due to the feasibility constraints, stating that $\mathrm{FA}^{*} x, \mathrm{FB}^{*} x$, $\mathrm{FC}^{*} x,(\mathrm{FA}+\mathrm{FB})^{*} x,(\mathrm{FA}+\mathrm{FC})^{*} x,(\mathrm{FB}+\mathrm{FC})^{*} x$ and $(\mathrm{FA}+\mathrm{FB}+\mathrm{FC})^{*} x$ have to be feasible, for $x=1 \pm f$. The problem involves now 12,214 continuous variables, 357 integer ones, 18,561 constraints with a sparsity of $99 \%$ in the constraint matrix, and requires $7000 \mathrm{~s}$ of CPU time.

Table 11

Gains for the three companies in scenarios 1 and 2.

\begin{tabular}{lll}
\hline Scenario & $\mathrm{GAV}_{\mathrm{ABC}}(\%)$ & \\
\cline { 2 - 3 } & $\mathrm{FABC}_{\mathrm{L}}$ & $\mathrm{FABC}_{\mathrm{U}}$ \\
\hline 1 & 13.5 & 13.9 \\
2 & 9.3 & 12.3 \\
\hline
\end{tabular}




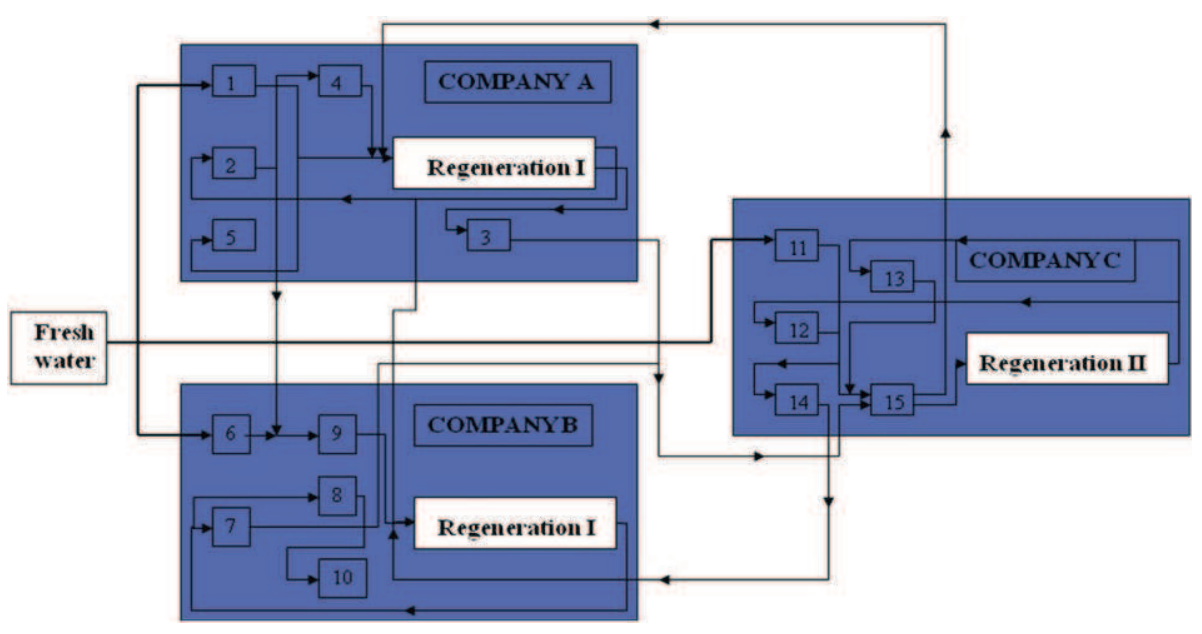

Fig. 5. EIP solution for scenario 1 . The output of units 5 and 10 going to the waste are not represented.

\section{Conclusion}

In a recent work (Boix et al., 2012), the best EIP involving three companies A, B and C was identified. The goal was the optimal management of their polluted waters. The problem was formulated as a triobjective MILP, where the fresh water flow rate $F_{1}$, the regenerated water flow rate $F_{2}$, and the number of connections $F_{3}$ have to be minimized. The best EIP involves 20 internal connections and six external ones (connections between two companies). The flexibility of the proposed solution, that is to say its capacity to take sudden variations in pollutant flow rates, is studied in this paper. The question which arises is to know if the retained solution remains economically profitable in case of increase/decrease of flow rates of polluted water. Two economic indicators are used for analyzing the EIP performances. The equivalent number of connections (ENC) which reflects the piping and pumping costs in the EIP infrastructure, and the Global Equivalent Cost (GEC) in fresh water flow rate which is expressed as an equivalent of fresh water flow rate in $\mathrm{T} / \mathrm{h}$.

Based on an EIP involving three companies, the goal of the paper is to give guidelines to face some variations of the economic activity. The model built is generic enough to be adapted for studying the flexibility of the water supply system for any EIP of any size, the only limitation is the size of the resulting MILP (in terms of number of variables and constraints). The study concerns any existing EIP, where the only changes are assumed to be related to the number of internal connections in companies (upgrading or adding regeneration units, changing process are not allowed). Finally, this study shows that in order to design optimal water network within an EIP, a numerical optimization can be an efficient tool, like GAMS for example, but a flexibility study of the proposed solutions is always required in practical world applications.

Indeed, numerical optimization can provide one solution, but is there really a practical interest of such solution, if it cannot change one iota from the values determined by the optimizer?

\section{Appendix. Mathematical model}

In most previous works, the water allocation problem for a company is generally solved with a MINLP monobjective optimization (Feng et al., 2008). Indeed, the problem contains bilinear terms due to products in mass balances for contaminants. These bilinearities are caused by products of concentrations and flow rates (Sienutycz and Jezowski, 2009). The modeling equations are the same as used in Boix et al. (2011a, 2011b), involving partial mass flows; that is to say that contaminants are represented by flow rates (in $\mathrm{g} / \mathrm{h}$ ) instead of concentrations (in ppm). The partial contaminant flow rate is linked to the contaminant concentration involving the partial water flow rate (in $\mathrm{T} / \mathrm{h}$ ) by this definition (assuming a flow stream going from process $j$ to process $k$ ), where fresh water inlet is represented by index $i=1$ and contaminant by $i=2$ :

$\frac{w_{2}^{j \rightarrow k}}{w_{1}^{j \rightarrow k}+w_{2}^{j \rightarrow k}}=C^{j \rightarrow k}$

The denominator $w_{1}^{j \rightarrow k}+w_{2}^{j \rightarrow k}$ represents the total flow rate of the stream. This term can be reduced regarding units of flow rates. Indeed, $w_{1}^{j \rightarrow k_{i}}$ is expressed in $\mathrm{T} / \mathrm{h}$ whereas $w_{2}^{j \rightarrow k}$ unit is $\mathrm{g} / \mathrm{h}\left(10^{-6} \mathrm{~T} / \mathrm{h}\right)$ what supports the relation (A2) and leads to the equation (A3) giving the definition for a partial contaminant flow rate.

$\frac{w_{2}^{j \rightarrow k}}{w_{1}^{j \rightarrow k}}=C^{j \rightarrow k}$

$w_{2}^{j \rightarrow k}=C^{j \rightarrow k} \times w_{1}^{j \rightarrow k}$

As a result of this assumption, the mass balances for flow rates are rewritten as follows - For a given process $j$, the inlet water $(i=1)$ flow rate is equal to the outlet water flow rate:

$$
\begin{aligned}
w_{1}^{j}+\sum_{k} \mathrm{wp}_{1}^{k \rightarrow j}+\sum_{m} \mathrm{wrp}_{1}^{m \rightarrow j}= & \mathrm{wd}_{1}^{j}+\sum_{k} \mathrm{wp}_{1}^{j \rightarrow k} \\
& +\sum_{m} \mathrm{wpr}_{1}^{j \rightarrow m}
\end{aligned}
$$

- For a given process $j$, the inlet contaminant $(i=2)$ flow rate plus the contaminant mass load is equal to the outlet contaminant flow rate:

$$
\begin{aligned}
& \sum_{k} \mathrm{wp}_{2}^{k \rightarrow j}+\sum_{m} \mathrm{wrp}_{2}^{m \rightarrow j}+\mathrm{M}_{2}^{j}=\mathrm{wd}_{2}^{j}+\sum_{k} \mathrm{wp}_{2}^{j \rightarrow k} \\
& \quad+\sum_{m} \mathrm{wpr}_{2}^{j \rightarrow m}
\end{aligned}
$$

- For a given regeneration unit $m$, the inlet water flow rate is equal to the outlet water flow rate: 
$\sum_{n} \mathrm{wr}_{1}^{n \rightarrow m}+\sum_{j} \mathrm{wpr}_{1}^{j \rightarrow m}=\operatorname{wrd}_{1}^{m}+\sum_{j} \mathrm{wrp}_{1}^{m \rightarrow j}+\sum_{n} \mathrm{wr}_{1}^{m \rightarrow n}$

- For a given regeneration unit $m$, the inlet contaminant flow rate is equal to the outlet contaminant flow rate:

$$
\sum_{n} w r_{2}^{n \rightarrow m}+\sum_{j} \mathrm{wpr}_{2}^{j \rightarrow m}=\operatorname{wrd}_{2}^{m}+\sum_{j} \mathrm{wrp}_{2}^{m \rightarrow j}+\sum_{n} \mathrm{wr}_{2}^{m \rightarrow n}
$$

- The overall fresh water flow rate is equal to the total discharged water flow rate:

$$
\sum_{m} \operatorname{wrd}_{1}^{m}+\sum_{j} \mathrm{wd}_{1}^{j}=\sum_{j} w_{1}^{j}
$$

- The total discharged contaminant flow rate is equal to the sum of contaminant mass loads of each process $j$ :

$$
\sum_{m} \operatorname{wrd}_{2}^{m}+\sum_{j} \mathrm{wd}_{2}^{j}=\sum_{j} M_{2}^{j}
$$

Equations (A10) and (A11) are used to introduce two new notations for the total inlet and outlet flow rates in a given process $j$.

$w_{i}^{j}+\sum_{k} \mathrm{wp}_{i}^{k \rightarrow j}+\sum_{m} \mathrm{wrp}_{i}^{m \rightarrow j}=\mathrm{wp}_{\mathrm{in}, i}^{j}$

$\sum_{k} \mathrm{wp}_{i}^{j \rightarrow k}+\sum_{m} \mathrm{wpr}_{i}^{j \rightarrow m}+\mathrm{wd}_{i}^{j}=\mathrm{wp}_{\text {out }, i}^{j}$

Given this set of mass balances equations, constraints on contaminant concentrations are added to the mathematical problem. Each process is limited vs. inlet and outlet contaminant concentration following these inequalities (for a process $j$ ):

$\mathrm{wp}_{\text {in }, 2}^{j} \leq \mathrm{Cmax}_{j}^{\mathrm{in}} \times \mathrm{wp}_{\text {in }, 2}^{j}$

$\mathrm{wp}_{\text {out }, 2}^{j} \leq \mathrm{Cmax}_{j}^{\text {out }} \times \mathrm{wp}_{\text {out }, 2}^{j}$

In the same way, the post-regeneration concentration is fixed and gives birth to equality (A14).

$\mathrm{wr}_{\text {out }, 2}^{m}=\mathrm{Cr}_{m}^{\text {out }} \times \mathrm{wr}_{\text {out }, 1}^{m}$

The addition of constraint (A13) is not without repercussions because it represents mass balances at splitters. Consequently, the output streams of a given process must have the same pollutant concentration and this assumption is mathematically conveyed for the outlet of a process $j$ as:

$$
\begin{aligned}
\mathrm{wp}_{2}^{j \rightarrow k}-C \max _{j}^{\text {out }} \times \mathrm{wp}_{1}^{j \rightarrow k} & =\mathrm{wpr}_{2}^{j \rightarrow m}-C \max _{j}^{\text {out }} \times \mathrm{wpr}_{1}^{j \rightarrow m} \\
& =\mathrm{wd}_{2}^{j}-C \mathrm{max}_{j}^{\text {out }} \times \mathrm{wd}_{1}^{j}
\end{aligned}
$$

In the same way, for the regeneration unit $m$, it comes:

$\mathrm{wr}_{2}^{m \rightarrow n}-\mathrm{Cr}_{m}^{\text {out }} \times \mathrm{wr}_{1}^{m \rightarrow n}=\mathrm{wrp}_{2}^{m \rightarrow j}-\mathrm{Cr}_{m}^{\text {out }} \times \mathrm{wrp}_{1}^{m \rightarrow j}$

However, these equalities hide an important condition. Indeed, if the mass flow of water is null for one stream, this stream does not exist, what is translated by the logic condition (A17): if $\mathrm{wp}_{1}^{j \rightarrow k}=0$ then $\mathrm{wp}_{2}^{j \rightarrow k}=0$

It changes equation (A15) in equation (A18), if the process $j$ does not distribute water to another process $k$; it comes:

$0=\mathrm{wpr}_{2}^{j \rightarrow m}-C \mathrm{max}_{j}^{\text {out }} \times \mathrm{wpr}_{1}^{j \rightarrow m}=\mathrm{wd}_{2}^{j}-C \mathrm{max}_{j}^{\text {out }} \times \mathrm{wd}_{1}^{j}$

Thus,

$\mathrm{wpr}_{2}^{j \rightarrow m}=\mathrm{Cmax}_{j}^{\text {out }} \times \mathrm{wpr}_{1}^{j \rightarrow m}$

The former demonstration changes the logic equation (A17) into the equality (A19), and thus, implies that outlet concentrations are equal to the maximal value $C \max _{j}^{\text {out }}$ for each process of the network. The above problem checks all the necessary optimality conditions for a single contaminant water allocation problem given by Savelski and Bagajewicz (2000). According to this formulation, the problem is linear. Nevertheless, in order to design the water supply network, a binary variable is assigned to each flow, what changes the problem into a MILP one. These variables $y$ are added in the program with the help of a big- $U$ constraint as ( $U$ has to be bigger than any water flow rate of the plant): $w_{i}^{j} \leq y_{i}^{j} \times U(\mathrm{~A} 20)$ Now, the problem has a mixed-integer linear form. For the case of an EIP, these equations are the same for each company included in the park.

The objectives functions are respectively: F1 the fresh water consumption, F2 the regenerated water flow rate and $F_{3}$ the number of connections in the network.

$$
\begin{aligned}
& F_{1}=\sum_{j} w_{1}^{j} \\
& F_{2}=\sum_{l}\left(\sum_{m} \mathrm{wr}^{m \rightarrow l}+\sum_{j} \mathrm{wpr}^{j \rightarrow l}\right) \\
& F_{3}=\sum_{k} y_{k}
\end{aligned}
$$

\section{References}

Advisory Council of Environment (ACE) of Hong Kong, paper 12/2005. Report on the 92nd environmental impact assessment subcommittee meeting.

Alexander, B., Barton, G., Petrie, J., Romagnoli, J., 2000. Process synthesis and optimisation tools for environmental design: methodology and structure. Comp. Chem. Eng. 24, 1195-1200.

Allenby, B., 2006. The ontologies on industrial ecology? Prog. Ind. Ecology, Int. J. 3 $(1-2), 28-40$.

Aviso, K.B., Tan, R.R., Culaba, A.B., 2010a. Designing eco-industrial water exchange networks using fuzzy mathematical programming. Clean Techn. Environ. Policy 12, 353-363.

Aviso, K.B., Tan, R.R., Culaba, A.B., Cruz Jr., J.B., 2010b. Bi-level fuzzy optimization approach for water exchange in eco-industrial parks. Process. Saf. Environ. Prot. $88,31-40$.

Baas, L., Boons, F., 2004. An industrial ecology project in practice: exploring the boundaries of decision-making levels in regional industrial systems. J. Clean. Prod. 12, 1073-1085.

Bagajewicz, M., Faria, D.C., 2009. On the appropriate architecture of the water wastewater allocation problem in process plants. Comp. Aided Chem. Eng. 26, $1-20$.

Bansal, V., Perkins, J.D., Pistikopoulos, E.N., 2002. Flexibility analysis and design using a parametric framework. AIChE J. 48, 2851-2868.

Boix, M., Montastruc, L., Pibouleau, L., Azzaro-PanteL, C., Domenech, S., 2011a. Eco industrial parks for water and heat management. ESCAPE 21. Comp. Aided Chem. Eng. 29, 1708-1712.

Boix, M., Montastruc, L., Pibouleau, L., Azzaro-PanteL, C., Domenech, S., 2011b. A multiobjective optimization framework for multicontaminant industrial water network design. J. Environ. Manag. 92, 1802-1810.

Boix, M., Montastruc, L., Pibouleau, L., Azzaro-Pantel, C., Domenech, S., 2012. Industrial water management by multiobjective optimization: from individual to collective solution through eco industrial parks. J. Clean. Prod. 22, 85-97. 
Chang, C.T., Riyanto, E., 2010. Revamp heuristics for improving operational flexibility of water networks. Comp. Aided Chem. Eng. 28

Chen, Y., Li, K.W., Xu, H., Liu, S., 2009. A DEA-TOPSIS method for multiple criteria decision analysis in emergency management. J. Syst. Sci. Syst. Eng. 28, 489-507. Chertow, M.R., 2007. "Uncovering” industrial symbiosis. J. Ind. Ecol. 11, 11-30.

Chew, I.M.L., Tan, R.R., Ng, D.K.S., Foo, D.C.Y., Majozi, T., Gouws, J., 2008. Synthesis of direct and indirect interplant water network. Ind. Eng. Chem. Res. 47, 9485-9496.

Chew, I.M.L., Tan, R.R., Foo, D.C.Y., Chiu, A.S.F., 2009. Game theory approach to the analysis of interplant water integration in an eco-industrial park. J. Clean. Prod. 17, 1611-1619.

Chew, I.M.L., Thillaivarrna, S.L., Tan, R.R., Foo, D.C.Y., 2011. Analysis of inter-plant water integration with indirect integration schemes through game theory approach: Pareto optimal solution with interventions. Clean. Techn. Environ. Policy 13, 49-62.

Conover, W.R., 1918. Salvaging and utilizing wastes and scrap in industry. Ind. M. 55.6, 449-451.

Côté, R., Cohen-Rosenthal, E., 1998. Designing eco-industrial parks: a synthesis of some experiences. J. Clean. Prod. 6, 181-188.

Feng, X., Bai, J., Wang, H.M., Zheng, X.S., 2008. Grass-roots design of regeneration recycling water networks. Comp. Chem. Eng. 32, 1892-1907.

Frosh, R.A., Gallopoulos, N.E., 1989. Strategies for manufacturing. Sci. Am. 261, 144152.

Geng, Y., Hengxin, Z., 2009. Industrial park management in the Chinese environment. J. Clean. Prod. 17, 1289-1294.

Gibbs, D., Deutz, P., 2005. Implementing industrial ecology? Planning for ecoindustrial parks in the USA. Geoforum 36, 452-464.

Gibbs, D., Deutz, P., 2007. Reflections on implementing industrial ecology through eco-industrial park development. J. Clean. Prod. 15, 1683-1695.

Giurco, D., Bossilkov, A., Patterson, J., Kazaglis, A., 2010. Developing industrial water reuse synergies in Port Melbourne: cost effectiveness, barriers and opportunities. J. Clean. Prod. 19, 867-876.

Heeres, R.R., Vermeulen, W.J.V., de Walle, F.B., 2004. Eco-industrial parks initiatives in the USA and the Netherlands: first lessons. J. Clean. Prod. 12, 985-995.

Hoffman, C., 1971. The Industrial Ecology of Small and Intermediate-sized Technical Companies: Implications for Regional Economic Development. Report prepared for the Economic Development Administration COM-74-10680, Texas University, USA.

Kim, S.H., Yoon, S.-G., Chae, S.H., Park, S., 2010. Economic and environmental optimization of a multi-site utility network for an industrial complex. J. Environ. Manag. 91, 690-705.

Liu, C., Zhang, K., Zhang, J., 2010. Sustainable utilization of regional water resources: experiences from the Hai Hua ecological industry pilot zone (HHEIPZ) project in China. J. Clean Prod. 18, 447-453.

Lovelady, E.M., El-Halwagi, M.M., 2009. Design and integration of eco-industrial parks for managing water resources. Environ. Prog. Sustain. Energ. 28, 265-272.

Mavrotas, G., 2009. Effective implementation of the $\varepsilon$-constraint method in multiobjective mathematical programming problems. Ap. Math. Comp. 213, 455-465.

Mirata, M., 2004. Experiences from early stages of a national industrial symbiosis programme in the UK: determinants and coordination challenges. J. Clean. Prod. 12, 967-983.
Oh, D.S., Kim, K.B., Jeong, S.Y., 2005. Eco-industrial park design: a Daedeok Technovalley case study. Habitat. Int. 29, 269-284.

Olesen, S.G., Polley, G.T., 1996. Dealing with plant geography and piping constraints in water network design. Trans. Chem. E. 74, 273-276.

Park, H.S., Rene, E.R., Choi, S.M., Chiu, A.S.F., 2008. Strategies for sustainable development of industrial park in Ulsan, South Korea - from spontaneous evolution to systematic expansion of industrial symbiosis. J. Environ. Manag. 87, 1-13.

PCSD (President's Council on Sustainable Development), 1996. Eco-efficiency Task Force Report. D.C, USA, Washington.

Ramirez, N., 2002. Valuing flexibility in infrastructure developments. The Bogota expansion plan. MSc thesis. MIT.

Report University of Southern California (USC), 2002. Resource Manual on Infrastructure for Eco-industrial Development.

Roberts, B.H., 2004. The application of industrial ecology principles and planning guidelines for the development of eco-industrial parks: an Australian case study. J. Clean. Prod. 12, 997-1010.

Savelski, M., Bagajewicz, M., 2000. On the necessary conditions of water utilization systems in process plants with single contaminants. Chem. Eng. Sci. 55, 50355048.

Shi, H., Chertow, M., Song, Y., 2010. Developing country experience with ecoindustrial parks: a case study of the Tianjin economical-technological development area in China. J. Clean. Prod. 18, 191-199.

Sienutycz, S., Jezowski, J., 2009. Energy Optimization in Process Systems - Chapter 20: Approaches to Water Network Design. 613-657. Elsevier, Oxford, UK.

Simmonds, P.L., 1862. Waste Products and Undeveloped Substances. Hardwicke, London.

Swaney, R.E., Grossmann, I.E., 1985. An index for operational flexibility in chemical process design. Part I. Formulation and theory. AIChE J. 31, 621-630.

Tiejun, D., 2010. Two quantitative indices for the planning and evaluation of ecoindustrial parks. Res. Conserv. Recycle 54, 442-448.

Tudor, T., Adam, E., Bates, M., 2007. Drivers and limitations for the successful development and functioning of EIPs (eco-industrial parks): a literature review. Ecol. Econ. 61, 199-207.

Van Beers, D., Corder, G., Bossilkov, A., Van Berkel, R., 2007. Industrial symbiosis in the Australian minerals industry: the cases of Kwinana and Gladstone. J. Ind. Ecol. 11, 55-72.

Van Berkel, R., 2007. Cleaner production and eco-efficiency initiatives in Western Australia 1996-2004. J. Clean. Prod. 15, 741-755.

Van Leeuwen, M.G., Vermeulen, W.J.V., Glasbergen, P., 2003. Planning eco-industrial parks: an analysis of Dutch planning methods. Bus. Strat. Environ. 12, 147-162.

Veiga, E. Bechara, L., Magrini, A. 2009. Eco-industrial park development in Rio de Janeiro, Brazil: a tool for sustainable development. J. Clean. Prod. 17, 653-661.

Watanabe, C., 1972. Industrial-Ecology: Introduction of Ecology into Industrial Policy. Ministry of International Trade and Industry (MITI), Tokyo.

Zhang, S., Babovic, V., 2009. Architecturing water supply system. A perspective from value of the flexibility. In: Second International Symposium on Engineering Systems. MIT, June, pp. 15-17.

Zhu, L., Zhou, J., Cui, Z., Liu, L., 2010. A method for controlling enterprises access to an eco-industrial park. Sci. Total Environ. 408, 4817-4825. 